\title{
Alleviating staff stress in care homes for people with dementia: protocol for stepped-wedge cluster randomised trial to evaluate a web-based Mindfulness- Stress Reduction course
}

\author{
Christine Baker ${ }^{1 *}$, Peter Huxley ${ }^{2}$, Michael Dennis ${ }^{1}$, Saiful Islam ${ }^{1}$ and lan Russell ${ }^{1}$
}

\begin{abstract}
Background: There has been continuing change in the nature of care homes in the UK with $80 \%$ of residents now living with some form of dementia or memory problem. Caring in this environment can be complex, challenging and stressful for staff; this can affect the quality of care provided to residents, lead to staff strain and burnout, and increase sickness, absence and turnover rates. It is therefore important to find interventions to increase the wellbeing of staff that will not only benefit staff themselves but also residents and care providers. Mindfulness training is known to be effective in treating a variety of physical and mental health conditions.

Methods and design: The study uses mixed methods centred on a stepped-wedge cluster randomised trial. Thirty care homes in Wales are implementing a brief web-based mindfulness training course, starting in random sequence. Four to ten consenting staff from each facility undertake the course and complete validated questionnaires at baseline and after eight and 20 weeks. We shall also interview a stratified sample of ten trained staff and analyse the transcripts thematically. The primary outcome is stress; secondary outcomes include job satisfaction, attitudes towards residents and sickness absence rates.
\end{abstract}

Discussion: With increasing numbers of people living with dementia in care homes and causing stress in their carers, it is important to evaluate support strategies for staff. Mindfulness-based therapies may be of potential benefit and need detailed examination.

Trial registration: ISRCTN registry. ISRCTN80487202. Registered 24 July 2013.

Keywords: Dementia, Challenging behaviour, Care homes, Care staff, Stress, Mindfulness, Stepped-wedge cluster randomised trial

\section{Background}

In 2000 Jennings [1] warned that one of the biggest challenges to health and welfare services over the next 50 years would be to improve the capacity to provide good care for people living with dementia (PLWD). Dementia has since become a challenge in both extent and impact. In 2014, around 835,000 people in the UK had a

* Correspondence: c.m.baker@swansea.ac.uk

${ }^{1}$ Swansea University Medical School, Swansea, UK

Full list of author information is available at the end of the article form of dementia; with an ageing population this number will increase [2].

More than $80 \%$ of older people are now living in residential and nursing homes have some form of dementia or memory problem [3]. Consequently long-term care for older people is mainly about care for dementia [4]. Whilst there are increasing numbers of residents living with dementia, the number of care home places has fallen in the last few years [5]. Projections of future demand suggest that more than double the current number of care home places will be required by 2043 to 
maintain the current ratio of institutional to community services for dementia [5].

The role of care homes in the UK has been changing over the past few years. This transformation was highlighted in an independent review established to recommend how to improve the training and support of both healthcare assistants working in hospitals, and social care workers in care homes and people's own homes [6].

This change in the nature of care homes has made considerable demands on the skills and training of their workforce. Providing care for PLWD has become a major industry for direct care providers, who are under pressure to ensure staff are suitably educated and trained to meet the needs of these residents. The UK Government is committed to improving dementia care by enhancing knowledge, skills, training and understanding of dementia amongst staff, as evidenced by the National Dementia Strategies in England [7], Northern Ireland [8], Scotland [9] and Wales [10]. However it may be difficult for care home providers to sustain a workforce that, whilst motivated to provide care under difficult conditions, may suffer work-related stress as a consequence. The mental health and wellbeing of staff may also affect staff turnover and sickness absence, and thus increase costs to providers.

In the UK in 2013-4, stress, depression or anxiety accounted for $39 \%$ of all work-related illnesses losing a total of 11.3 million working days. The occupations that reported the highest prevalence of stress-related illness were health and social care associate professionals [11].

Nursing has long been considered one of the most stressful professions [12-14]. The main stressors include long hours, heavy workload, lack of influence within the workplace, insufficient resources, role ambiguity, experiences of aggression [15], the effects of death and dying [16], and lack of support and recognition from coworkers and management [17]. Yet dominant nursing philosophies emphasise a humanistic caring paradigm that requires them to develop profound interpersonal understanding and sensitivity to provide effective care [18]. This dilemma can also apply to staff working in care homes who have similar stressors, and are also poorly paid. An influential social care workforce study estimated that about $10 \%$ of the care workforce in England received less than the national minimum wage [19]. Care staff may also have zero-hour contracts which oblige them to work all shifts offered, often without holiday or sick pay [20].

Care workers are crucial to the quality of care and quality of life of PLWD in care homes, and the relationship between residents and caregivers is central to this quality [21]. However caring for PLWD can be stressful and challenging for staff [22-24]. As well as the complex physical requirements, up to $40 \%$ of staff time is spent managing challenging resident behaviour [23, 25, 26]. This behaviour occurs in at least $75 \%$ of people with dementia and may become more severe over time [27]. This contributes to staff stress, strain [23, 24, 28] and potentially to staff turnover. Consequently, residents have staff who are less willing to help, low in optimism and show negative emotional responses to clients' behaviour [29].

Work stress is described as "adverse reactions to excessive pressures or other types of demand" [30]. Although there is controversy about the mechanisms of occupational stress, the dominant models - demandcontrol [31] and effort-reward [32] - explain it as an imbalance between these factors. The resultant effects of stress on individuals are mediated by personal factors like age, experience, health and coping skills [33-35].

The National Institute for Health and Care Excellence (NICE) has published two public health guidelines relevant to mental health in the workplace - Managing Long Term Sickness and Incapacity [36] and Promoting Mental Wellbeing at Work [37] - and recommended more evidence-based research, focused not only on organisations but also on individuals [37].

Whilst there has been research on stress in families caring for relatives with dementia, there are few studies of stress in long-term care staff [38]. One study examined stress in staff caring for residents with dementia across long-term care facilities in the USA [22]. Results showed that stress was reported more often by those employed for less than 2 years even though their attitudes towards dementia were more positive. The authors also found job satisfaction to be higher amongst staff who had received more training in assessment or who practised person-centred care (PCC) [22].

A systematic review in the Netherlands [39] showed that PCC generally increased job satisfaction and personal accomplishment, and reduced job demands and emotional exhaustion: one study found that PCC reduced sickness absence and two found that it reduced stress. The authors argued for more research into care homes with longer follow-up periods [39].

Despite studies of sources and levels of stress amongst health care professionals, little is known about effective ways to moderate or eliminate these stressors [40]. A rigorous review of interventions for reducing occupational stress amongst health care workers found that only two of 14 trials were of high quality and concluded that more rigorous research is needed [41].

Mindfulness-based stress reduction (MBSR) is an intervention that has been reported to be beneficial in the treatment of many physical and mental health problems [42, 43]. It is effective in the stress management of healthy people and helps to increase empathy and self- 
compassion [44]. There is evidence to suggest that mindfulness practice is effective in reducing stress and decreasing burnout amongst healthcare professionals including nursing staff [45] and has a positive impact on job satisfaction [46]. However there is very little evidence of the use of MBSR by care staff and nurses in long term care settings and its effects.

MBSR is a psycho-educational programme that typically comprises eight weekly classroom-based sessions lasting about $2 \mathrm{~h}$ and a whole-day retreat towards the end. The programme includes taught meditation practices, and exploits the group format by sharing and discussing the challenges and experiences of incorporating mindfulness into daily lives and stressful situations. However we needed to enable staff to attend group sessions despite geography, time pressures and the costs of attending a group course, which range between $£ 200$ and $£ 350$ per person [47].

Alternatives to the traditional method of teaching MBSR include synthesising the main elements, thus reducing the length of the programme [18]. Web-based MBSR training has also been developed; one study showed no difference in outcomes between MBSR participants who attended in person and those who trained online [48]. A feasibility study [47] and a randomised pilot study [49] both concluded that the online course was an accessible and acceptable way to reduce stress.

\section{Research objectives}

\section{Primary objective}

To evaluate the effectiveness of web-based mindfulness training in reducing staff stress in care homes with people living with dementia.

\section{Secondary objectives}

To evaluate the effects of mindfulness training on: job satisfaction; staff attitudes to dementia; sickness absence; and its cost-effectiveness taking account of the time staff take to complete the course.

\section{Ethical approval}

The Research Ethics Committee of the College of Human and Health Sciences of Swansea University approved this protocol. Informed written consent and permission to publish any direct quotes from interviews or focus groups will be obtained from each participant prior to the onset of the study.

\section{Design and methods}

The basic design is a stepped-wedge cluster randomised trial, also known as a randomised multiple interrupted time series. A trial of this nature rolls the chosen intervention out to clusters and their members in a random sequence over time [50]. Accordingly once every week or so we shall initiate a brief web-based mindfulness training programme for staff (who together form a 'cluster') in one of 30 participating care homes across Wales that are registered to care for PLWD, until all 30 have received the intervention. The Swansea Trials Unit (STU) will give each home an identification number to maintain anonymity and generate the random sequence stratified by area (South East, South West, North or Mid Wales) and type of care home (private, local authority or voluntary not for profit) (Fig. 1).

Though we know of no data on intra-cluster correlation coefficients (ICCCs) for stress in care home staff, our previous experience of cluster trials in care homes suggests that ICCCs are unlikely to exceed 0.05 [51]. So we estimate that if four consented staff in each of 30 trial homes report their stress levels before they start mindfulness training and eight and 20 weeks thereafter, the trial will have more than $80 \%$ power to detect an improvement in stress equivalent to an effect size of 0.3 (generally regarded as a small effect).

In implementing this design, we shall conceal each home's random start until 6 weeks before that date. We shall then inform managers by phone of the timing of their mindfulness training and arrange a visit to recruit and consent participating staff and show them how to access and use the online mindfulness training course.

\section{Recruitment}

The Care \& Social Services Inspectorate of Wales (CSSIW) provided a list of the 403 care homes in Wales registered to care for PLWD. We surveyed a random sample of 134 (33 \%) of these. Of the 72 (54 0025) who responded, we selected a random sample of 35 to participate in the trial, thus permitting the immediate replacement of any of the 30 consenting homes who withdrew before starting.

We sent information sheets to care home managers to explain the trial and phoned interested managers to answer their questions and discuss the recruitment of staff to participate in the trial. We then attended staff meetings to explain mindfulness and gain voluntary participation.

\section{Inclusion and exclusion criteria}

Of the care homes registered with CSSIW to care for PLWD, we excluded those with fewer than 16 beds to yield enough staff for mindfulness training. In 30 consenting homes we approached managers and staff who provide direct care for residents. We sought to recruit at least four and at most ten staff, including at least one nurse where possible and at least two other care staff, to undertake mindfulness training and complete questionnaires before training and 8 and 20 weeks thereafter (Fig. 2). 


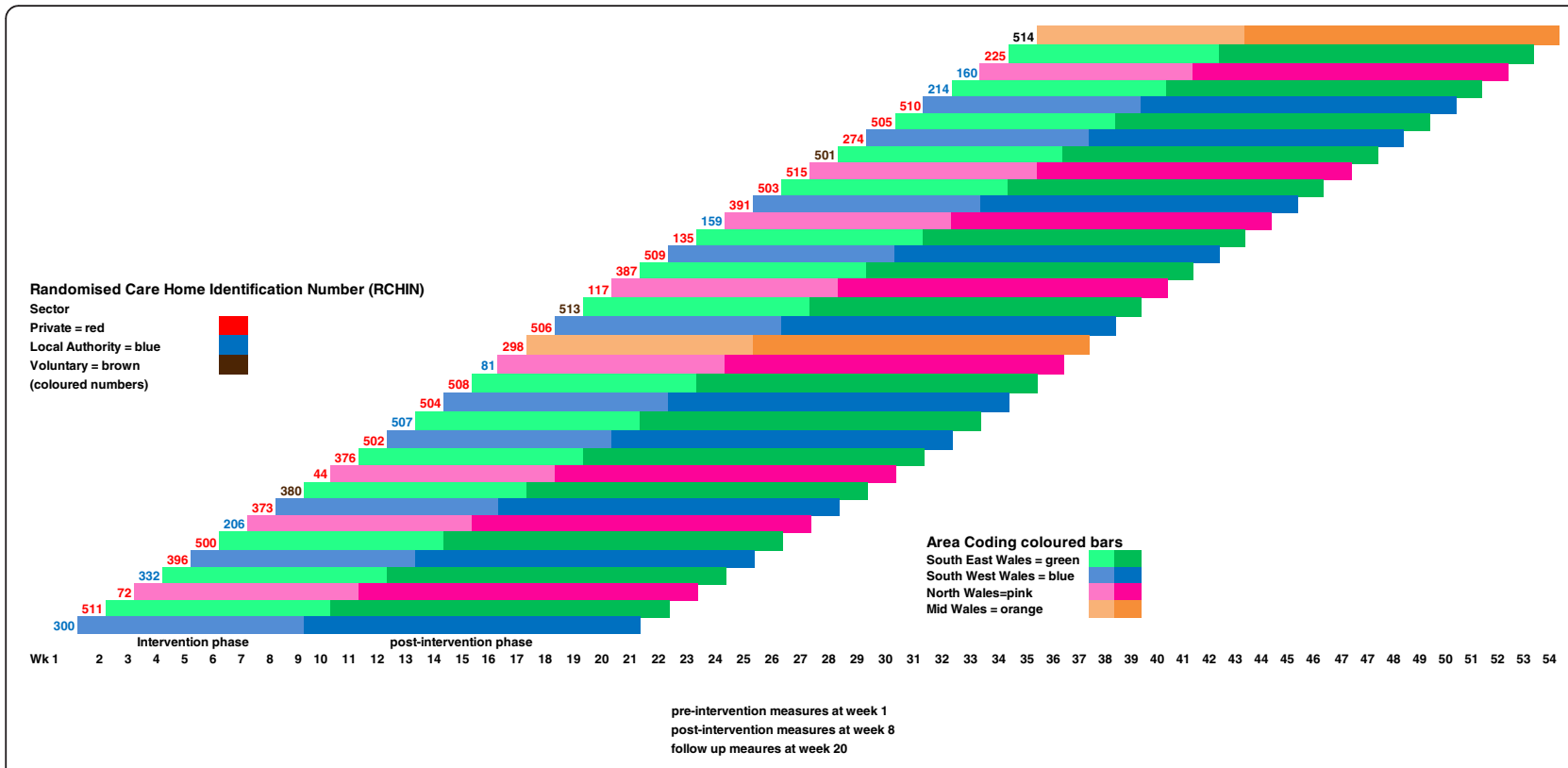

Fig. 1 Stepped-Wedge Trial. Random sequence stratified by area and type of care home

\section{Intervention}

Table 1 below summarises the web-based mindfulness training course, organised by the Mental Health Foundation through Wellmind Media [52]. It combines elements of both Mindfulness-Based Stress Reduction (MBSR) [53] and Mindfulness-Based Cognitive Therapy (MBCT) [54].

The main features include:

- Ten sessions each lasting 30 min with videos and interactive exercises led by leading mindfulness trainers.

- Twelve assignments to practice in daily life with supporting emails.

- Five guided meditation audio downloads.

- Online tools for reviewing progress.

- A course completion certificate.

- An overview

- An aftercare pack sent by post including a printed guide to everyday mindfulness.

The course may be completed within 4 weeks but it can be done at a convenient pace as there is no limit to completion. It teaches formal meditation skills and informal techniques that can be incorporated into daily activities.

Participants can take breaks from the course and repeat any part at any time. If so they receive emails to remind them where they have reached. The software asks them to practice formal meditation exercises they have learned using the audio and video clips supplied, ideally every day.

Participants can monitor their progress in terms of stress, anxiety and depression, using measures intrinsic to the online course at the start and end, and at 1 month following completion. The measures include the Perceived Stress Scale [55], the Generalised Anxiety Disorder Assessment Scale (GAD-7) [56] and the Patient Health Questionnaire (PHQ-9) [57]. There is also an email address and telephone number for general and technical support.

\section{Measures used in the trial}

The demographic and related data we collect include age, gender, ethnic origin, education, work status, training in dementia care (type, length and recency), care experience (both length and number of previous posts, with and without residents with dementia), and type and size of current care home.

\section{Outcome measures}

At baseline, 8 weeks and 20 weeks we use seven validated measures to explore stress, job satisfaction and attitudes to residents with dementia. We complement these with qualitative data, reported sickness absence and reported costs.

\section{Primary outcome measures - stress}

1) The Work Stress Inventory [58] has studied stress in staff of long-term care facilities in the USA [22]. It estimates the average frequency of 45 stressors across six domains - events, caring for residents, working relationships, supervisory relationships, workload and the caring environment.

2) The Karasek Job Content Questionnaire [59] was designed to assess the effects of stressful jobs on the health of employees. It is well validated and widely used and has been used in several countries with different 


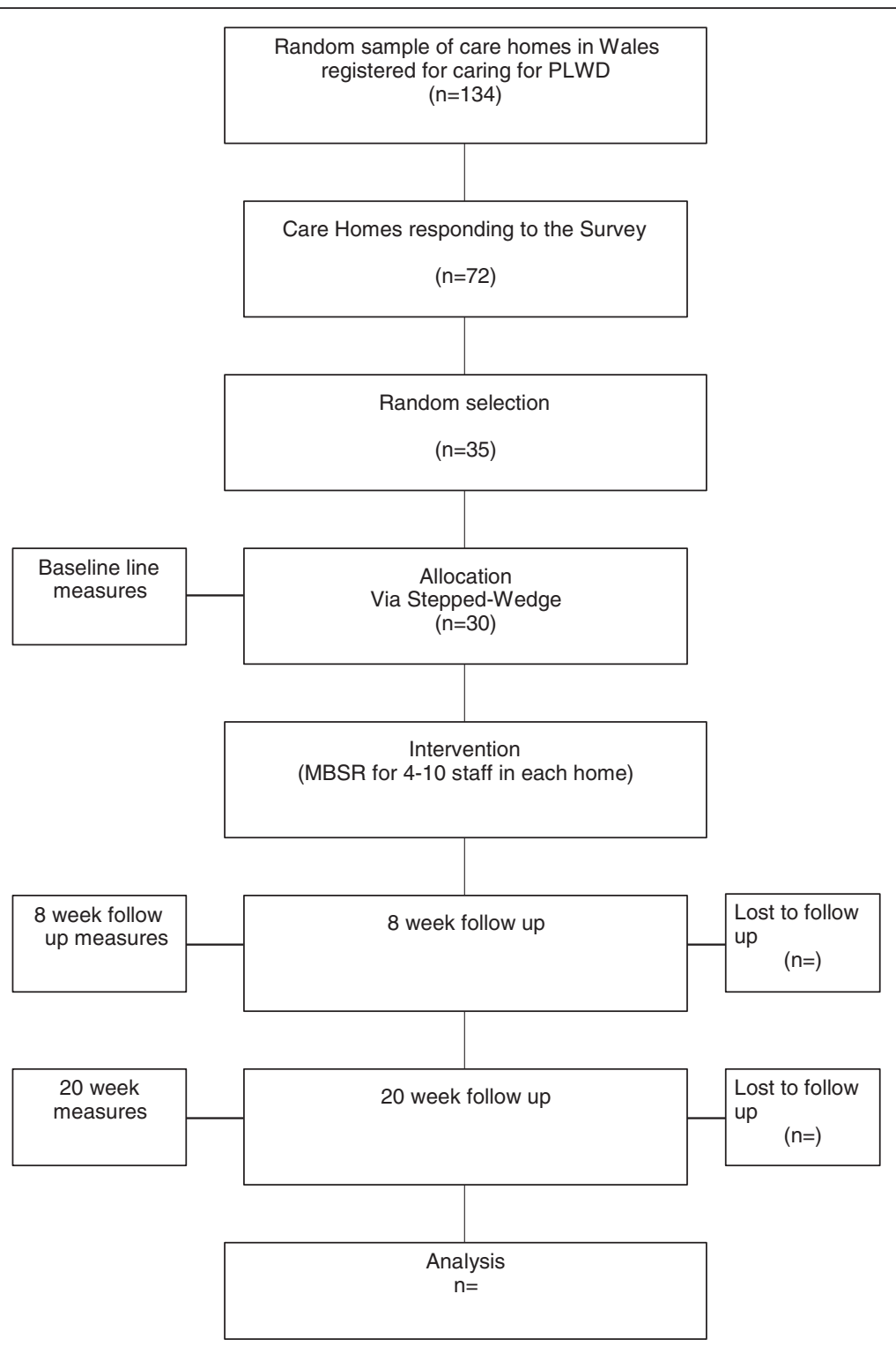

Fig. 2 Flow Chart of recruitment process

economic and social characteristics. It comprises four scales - decision latitude (comprising two subscales skill discretion and decision authority), psychological demands, physical demands and social support (comprising two subscales -support from colleagues and supervisors). Job strain arises from the combination of high demands and low decision latitude. Generic strain arises from the combination of high demands, low decision latitude and low social support.

\section{Secondary outcome measures}

\section{1: Job satisfaction}

a) Staff Experience of Working with Demented Residents [60] uses 21 five-point items to assess satisfaction across six domains - feedback, the care organisation, ones' own expectations, resident contact, the expectations of others and the environment.

b) Satisfaction with Job Facets [61] uses five sevenpoint items to measure job satisfaction - with the job, with co-workers, with the work itself, with the place of work, and with the resources including equipment and supervision.

\section{2: Attitudes to dementia}

The Approaches to Dementia Questionnaire [62] aims to discover respondents' attitudes towards PLWD. It uses 19 five-point items to yield a total score and 2 sub-scores. The Person-Centredness (PC) dimension comprises 11 items assessing how the respondent acknowledges and 
Table 1 Main programme components of mindfulness training

\begin{tabular}{|c|c|c|c|c|}
\hline & Week 1 & Week 2 & Week 3 & Week 4 \\
\hline & Introduction & & & \\
\hline & Orientation & & & \\
\hline & Stress Assessment & & & \\
\hline \multirow[t]{2}{*}{ Theme } & Stepping out of & Reconnecting with & Working with & Mindfulness \\
\hline & Automatic Pilot & Body and Breath & Difficulties & in Daily Life \\
\hline \multirow[t]{6}{*}{ Exercises } & Routine activity & Mindful movement & Breathing Space & Breathing \\
\hline & Mindful eating & Mindful Breathing & Sitting meditation & Space and action step \\
\hline & Body Scan & Event Awareness & Stress Awareness & Activity \\
\hline & & & & Awareness \\
\hline & & & & Stress \\
\hline & & & & Strategies \\
\hline
\end{tabular}

reacts to PLWD as unique individuals; for example Question 11 states 'people with dementia need to feel respected, just like anybody else'. The hope dimension comprises eight items and assesses whether the respondent is optimistic or pessimistic towards the abilities and the future of people with dementia; for example Question 3 states 'there is no hope for people with dementia'. The scale is both consistent (Cronbach's alpha $=0.83$ ) and reliable (test-retest reliability $=0.76$ ) [48].

\section{3: Health interference with work}

The Stanford Presenteeism Scale 6 (SPS6) [63] uses six five-point items to measure the respondent's "presenteeism", defined as "ability to concentrate on and accomplish work despite health problem(s)" [60].

\section{4: Physical and mental wellbeing}

The Short Form Health Survey (SF-12) [64] enables respondents to report their perceived wellbeing through eight concepts - physical functioning, role functioning physical, bodily pain, general health, vitality, social functioning, role functioning emotional, and mental health. These yield two meta-scores - Physical Component Summary (PCS) and Mental Component Summary (MCS) - each with a range of 0 to 100 , and a mean of 50 and a standard deviation of 10 in a representative sample of the US population.

\section{5: Qualitative data}

We want to explore the subjective experience of staff working in a care home in terms of stress and coping. As the web-based mindfulness programme is a novel way of reducing staff stress in this setting, we shall also ask participants about their experience of undertaking the training. To collect these qualitative data we shall conduct one-to-one semi-structured interviews with a sample of ten staff who consented to participate in the mindfulness training, stratified by the number of weeks they completed. This method will allow the participants to speak for themselves, complement the quantitative questions, and raise issues that may have not been previously considered. Table 2 shows the interview schedule: the first section covers questions about stress and coping in the care home; and the second asks questions about the web-based course itself.

We shall record the interviews digitally and transcribe them verbatim. We shall use the Computer Aided Qualitative Data Analysis Software (CAQDAS), NVivo 10, for data management and thematic analysis. We shall illustrate findings by anonymised quotations showing how mindfulness training affected respondents' feelings of stress and wellbeing.

\section{6: Sickness absence rates}

To examine the effects of the course on sickness absence rates, we shall ask managers for data from 3 months prior to the intervention until the 20-week follow up

\section{7: Costs}

We shall estimate the costs of the intervention from discussions with providers and staff. Specifically we shall ask participating staff to report their use of health and social care and then use published unit costs to translate their responses into costs. We shall compare the resulting marginal cost of mindfulness training with its marginal benefit derived from the SF-6D [54], a by-product of the SF-12. Thus we shall estimate the cost per Quality-adjusted life year (QALY) gained by mindfulness training, the evaluative criterion favoured by the (British) National Institute of Health \& Care Excellence (NICE).

\section{Statistical analysis}

We shall analyse changes in all outcome measures between baseline and follow-up at 8 or 20 weeks by analysis of covariance. As covariates, we shall use the pretraining values of the outcome measure under analysis 
Table 2 Qualitative interview schedule

A. Stress and coping in the care home
1 What do you think are the issues that cause you stress at work?
2 What sort of personal feelings do you have about working in a care
home?
3 If you had any negative feelings, how would you have normally dealt
with them?
4 Do you think that this was effective?
B. Experience of the Be Mindful course.
5 How did you feel about the course as a whole? (access, instructions,
length of time taken, time negotiated with the manager to do the
course)
6 What about the content of the course? Is there a specific type of
practice that you feel benefited you most?
7 Did you personally feel any changes in your stress, anxiety or
depression as a result of what you practiced or learned from the
mindfulness course?
8 Do you think that this practice would help to reduce sickness/absence
rates?
9 Are you still practicing some of the aspects you were taught on the
course like mindfulness breathing?
10 Would you recommend this course or anything similar to colleagues
or friends who were complaining of stress, anxiety or depression? If
so why and if not, why not?
11 If you could change anything about the course, what would you
suggest?
12 Is there anything else you would like to add?

and consider participants' age, gender, ethnic origin, education and work status, and features of their training in dementia care, care experience and current care home.

We shall check the internal consistency of these outcome measures by Cronbach's alpha, and explore relationships between them by multiple linear regression. Where individual items are missing from outcome measures, we shall follow the published instructions for imputation if any; otherwise we shall use the SPSS Missing Value module.

\section{Discussion}

The increasing number of people living with dementia (PLWD) in care homes and the need to protect these residents' quality of life require us all to consider the wellbeing of staff. Very few studies have investigated stress in staff who care for PLWD in care homes. We know little about effective ways to ameliorate this stress. This trial will extend our knowledge by evaluating whether online mindfulness training reduces stress and improves job satisfaction and attitudes to dementia.

The advantage of using online training in this environment is that staff can access the course when convenient and at their own pace, and immediately use techniques learned in their practice. The trial participants include managers, qualified nurses, senior care workers and support staff with heterogeneous training, responsibilities and work patterns. Hence we plan to examine factors that influence stress and the effects of mindfulness training.

A major strength of the study is that the data come from a nationally representative random sample of care facilities for PLWD. In addition we are using mixed methods. Quantitative methods are valuable and have been used in several studies to evaluate the effects of MBSR in both clinical and non-clinical contexts. However those studies neglected subjective experiences of participants. Hence our use of qualitative interviewing will yield additional information and insights into the challenges of delivering MBSR to this population.

\section{Limitations and challenges}

We are conscious that research in care homes is a complex undertaking which will require us to take account of the needs of residents, relatives and staff; and that participation in research may not be a priority for managers and staff who have high workloads [65].

The MBSR course requires a quiet room to listen to instructions and learn meditation practices. Participating staff also need access both to computers and the internet within their care homes. Time for undertaking MBSR training, and for completing questionnaires, also needs negotiation. We have addressed these issues in consultation with care home managers.

The web-based course is designed to take 4 weeks but staff can pause and restart at any time, so we shall not expect all staff to complete the course within the defined study period of 8 weeks. We shall therefore analyse whether the effectiveness of training is associated with participants' rate of progress through the course.

We recognise that managers may be cautious about divulging information about sickness absence rates. We shall try to overcome this reluctance by spending time with staff to gain trust and confidence.

Despite these challenges, the result of the study will provide valuable evidence whether MBSR is an effective and cost-effective intervention in this organisational setting. If web-based mindfulness training proves effective in care homes, it would be important to consider whether to extend this training to informal and formal carers of PLWD across primary and secondary care who prefer web-based training or cannot attend traditional mindfulness courses.

\section{Abbreviations}

CSSIW: Care and Social Services Inspectorate for Wales; MBCT: MindfulnessBased Cognitive Therapy; MBSR: Mindfulness- Based Stress Reduction; MCS: SF-12 Mental Component Summary; NICE: (British) National Institute of Health \& Care Excellence; NIHR: National Institute for Health and Care Excellence; PC: Person centredness; PCC: Person-centred care; PCS: SF-12 Physical Component Summary; PLWD: People living with dementia; QUALY: Quality-adjusted life year; STU: Swansea Trials Unit. 


\section{Competing interests}

The authors declare they have no competing interests.

\section{Authors' contributions}

$C B$ is the primary investigator, who conceived the study, obtained funding, designed and co-ordinated the study and mindfulness training, collected and managed the data, and drafted and revised the manuscript. PH contributed to the design and conduct of the study and mindfulness training and revised the manuscript. MD advised on the psychological aspects of the study and revised the manuscript. MSI developed the analysis plan and revised the manuscript. IR designed the trial and revised the manuscript. All authors are members of the research management group and have approved the final version of the manuscript.

\section{Acknowledgements}

The authors thank Health \& Care Research Wales for the funding, the Care and Social Services Inspectorate of Wales (CSSIW) and My Home Life Cymru for support, and the managers and staff of participating care homes in Wales for their essential and valued time.

\section{Author details}

${ }^{1}$ Swansea University Medical School, Swansea, UK. ${ }^{2}$ Centre for Mental Health and Society, Bangor University, Bangor, Gwynedd, UK.

\section{Received: 25 November 2015 Accepted: 16 December 2015 Published online: 21 December 2015}

\section{References}

1. Jennings B. A life greater than the sum of its sensations: ethics, dementia and quality of life. In: Albert SM, Logsdon RG, editors. Assessing quality of life in Alzheimer's disease. New York: Springer Publishing Company; 2000. p. 165-78.

2. Society A's. Dementia 2014: opportunity for change. London: Alzheimer's Society; 2014. http://www.alzheimers.org.uk/site/scripts/download_info. php?fileID=2317. Accessed 3 Aug 2015.

3. Society A's. Low expectations: attitudes on choice, care and community for people with dementia in care homes. London: Alzheimer's Society; 2013. http://www.alzheimers.org.uk/site/scripts/download_info.php?filelD=1628. Accessed 9 Jan 2015

4. Prince M, Prina M, Guerchet M. World Alzheimer Report 2013: journey of caring - analysis of long-term care for dementia. London: Alzheimer's Disease International; 2014. http://www.alz.co.uk/research/world-report-2013. Accessed 4 Aug 2015.

5. Lievesley N, Crosby G, Bowman C, Midwinter E. The changing role of care homes. London: BUPA and Centre for Policy on Ageing; 2011. http:/www.cpa.org.uk/ information/reviews/changingroleofcarehomes.pdf. Accessed 12 March 2015.

6. Cavendish C. The Cavendish review: an independent review into healthcare assistants and support workers in the NHS and social care settings. London: DH; 2013. https:/www.gov.uk/government/publications/review-of-healthcareassistants-and-support-workers-in-nhs-and-social-care. Accessed 19 Jan 2015.

7. Department of Health. Living well with dementia: a National Dementia Strategy. London: DH; 2009. https://www.gov.uk/government/publications/ living-well-with-dementia-a-national-dementia-strategy. Accessed 19 Jan 2015.

8. Department of Health, Social Services and Public Safety. Improving Dementia Services in Northern Ireland: A Regional Strategy. Belfast: DHSSPS; 2011. https://www.dhsspsni.gov.uk/publications/improving-dementiaservices-northern-ireland-regional-strategy. Accessed 19 Jan 2015.

9. Scottish Government. Scotland's National Dementia Strategy 2013-16. Edinburgh: SG; 2011. http://www.scotland.gov.uk/Resource/0042/00423472. pdf. Accessed 19 Jan 2015

10. Welsh Assembly Government. National Dementia Vision for Wales: Dementia Supportive Communities. Cardiff: WAG; 2011. http://gov.wales/ docs/dhss/publications/110302dementiaen.pdf. Accessed 19 Jan 2015.

11. Health and Safety Executive. Stress-related and psychological disorders in Great Britain 2014. London: HSE; 2015. http://www.hse.gov.uk/statistics/ causdis/stress/. Accessed 19 Jan 2015.

12. Selye H. The stress of life. New York: McGraw-Hill; 1956

13. Albrecht TL. What job stress means for the staff nurse. Nurs Adm Q. 1982;7:1-11.

14. Lambert VA, Lambert CE. Literature review of role stress/strain on nurses: an international perspective. Nurs Health Sci. 2001;3:161-72.

15. Lim J, Bogossian F, Ahem K. Stress and coping in Australian nurses: a systematic review. Int Nurs Rev. 2010;57:22-31.
16. Wilson J, Kirshbaum M. Effects of patient death. Br J Nurs. 2011;20:559-63.

17. Lewis R, Yarker J, Donaldson-Feilder E, Flaxman P, Munir F. Using a competency-based approach to identify the management behaviours required to manage workplace stress in nursing: a critical incident study. Int J Nurs Stud. 2010;47:307-13.

18. Corey S, Mackenzie CS, Poulin PA, Seidman-Carlson R. A brief mindfulnessbased stress reduction intervention for nurses and nurse aides. Appl Nurs Res. 2006;19:105-9.

19. Hussein S. Estimating probabilities and numbers of direct care workers paid under the National Minimum Wage in the UK: a Bayesian approach. Social Care Workforce Periodical Issue 16. London: Social Care Workforce Research Unit, King's College; 2011.

20. Unison. Zeroing in on zero-hours contracts. London: Unison; 2014. http://www. unison.org.uk/zeroing-in-on-zero-hours-contracts Accessed 19 Jan 2015.

21. Bowers $B$, Fibich $B$, Jacobson $N$. The relationship between staffing and quality in long-term care facilities: exploring the views of nurse aides. J Nurs Care Qual. 2000;14:55-64.

22. Zimmerman S, Williams CS, Reed PS, Boustani M, Preisser JS, Heck E, et al. Attitudes, stress and satisfaction of staff who care for residents with dementia. Gerontologist. 2005;45:96-105.

23. Kleinman L, Frank L, Ciesla G, Rupnow M, Brodaty H. Psychometric performance of an assessment scale for strain in nursing care: The M-NCAS. Health Qual Life Outcomes. 2004;2:1-10.

24. Brodaty H, Draper B, Low LF. Nursing home staff attitudes towards residents with dementia: strain and satisfaction with work. J Adv Nurs. 2003;44:583-90.

25. Lann-Wolcott $H$, Medvene L. Measuring the person-centredness of caregivers working with nursing home residents with dementia. Behav Ther. 2011;42:89-99.

26. Mackenzie CS, Peragine G. Measuring and enhancing self-efficacy among professional caregivers of individuals with dementia. Am J Alz Dis Other Dement. 2003;18:291-8.

27. Talerico K, Evans L, Strumpf N. Mental health correlates of aggression in nursing home residents with dementia. Gerontologist. 2002;42:169-77.

28. Edberg A, Bird M, Richards DA, Woods R, Keeley P, Davis-Quarrell V. Strain in nursing care of people with dementia: nurses' experience in Australia, Sweden and United Kingdom. Aging Ment Health. 2008;12:236-43.

29. Todd SJ, Watts SC. Staff responses to challenging behaviour shown by people with dementia: application of an attributional-emotional model of helping behaviour. Aging Ment Health. 2005:9:71-81.

30. Health and Safety Executive. http://www.hse.gov.uk/stress/furtheradvice/ whatisstress.htm. Accessed 19 Jan 2015.

31. Karasek R. The stress-disequilibrium theory: chronic disease development, low social control, and psychological de-regulation. Med Lav. 2006;97:258-71.

32. Siegrist J. Adverse health effects of high-effort/low-reward conditions. J Occup Health Psychol. 1996; 1:27-41.

33. Cooper C, Dewe P, O'Driscoll MP. Organizational stress: a review and critique of theory, research and applications. London: Sage; 2001.

34. Schaufeli WB, Buunk BP. Burnout: an overview of 25 years of research and theorizing. In: Schabracq MJ, Winnubst JAM, Cooper CL, editors. The handbook of work and health psychology. Chichester: Wiley; 2003. p. 383-425.

35. Bamber MR. CBT for occupational stress in health professionals: introducing a schema-focused approach. Hove: Routledge; 2006.

36. National Institute for Health and Clinical Excellence. Managing long-term sickness and incapacity for work. NICE Guideline PH19. London; NICE: 2009. http://www.nice.org.uk/GUIDANCE/PH19. Accessed 19 January 2015.

37. National Institute for Health and Clinical Excellence. Promoting mental wellbeing at work. NICE Guideline PH22. London; NICE: 2009. http://www. nice.org.uk/GUIDANCE/PH22. Accessed 19 January 2015.

38. McCarty EF, Drebing C. Exploring professional caregivers' perceptions: Balancing self-care with care for patients with Alzheimer's disease. J Gerontol Nurs. 2003;29:42-8.

39. Van den Pol-Grevelink A, Jukema JS, Smits CHM. Person-centred care and job satisfaction of caregivers in nursing homes: a systematic review of the impact of different forms of person-centred care on various dimensions of job satisfaction. Int J Geriatr Psychiatry. 2011;27:219-29.

40. Ruotsalainen JH, Serra C, Marine A, Verbeek JH. Systematic review of interventions for reducing occupational stress in health care workers. Scand J Work Environ Health. 2008;34:169-78.

41. Edwards D, Burnard P. A systematic review of stress and stress management interventions for mental health nurses. J Adv Nurs. 2003;42:169-200. 
42. Baer RA. Mindfulness training as a clinical intervention: a conceptual and empirical review. Clin Psychol Sci Pract. 2003;10:125-43.

43. Grossman P, Niemann L, Schmidt S, Walach H. Mindfulness-based stress reduction and health benefits: a meta-analysis. J Psychosom Res. 2004;57:35-43.

44. Chiesa A, Serretti AJ. Altern Complement Med. 2009;15:593-600.

45. Cohen-Katz J, Wiley SD, Capuano T, Baker DM, Shapiro S. The effects of mindfulness-based stress reduction on nurse stress and burnout: a quantitative and qualitative study. Holist Nurs Pract. 2004;18:302-8.

46. Im Choi J, Koh MS. Relations of Job Stress, Burnout, Mindfulness and Job Satisfaction of Clinical Nurses. Int J Biosci Biotechnol 2015; 7:121-8. http:// www.sersc.org/journals/IJBSBT/vol7_no3/12.pdf. Accessed Nov 302015

47. Krusche A, Cyhlarova E, Williams JMG. Mindfulness online: an evaluation of the feasibility of a web-based mindfulness course for stress, anxiety and depression. BMJ Open. 2012;2:e000803. doi:10.1136/bmjopen-2011-000803.

48. Wolever RQ, Bobinet KJ, McCabe K, Mackenzie ER, Fekete E, Kusnick CA, et al. Effective and viable mind-body stress reduction in the workplace: a randomized controlled trial. J Occup Health Psychol. 2012;17:246-58.

49. Gluck TM, Maercker A. A randomized controlled pilot study of brief webbased mindfulness training. BMC Psychiatry. 2011;11:175.

50. Brown CA, Lilford RJ. The stepped wedge trial design: a systematic review. BMC Med Res Methodol. 2006;6:54. doi:10.1186/1471-2288-6-54.

51. Moxon S, Lyne K, Sinclair I, Young P, Kirk C. Mental health in residential homes: a role for care staff. Ageing Soc. 2001;21:71-93.

52. Be Mindful. Online Mindfulness Course. http://www.bemindfulonline.com/. Accessed Feb 2015.

53. Kabat-Zinn J. Full catastrophe living: using the wisdom of your body and mind to face stress, pain and illness. New York: Delacorte; 2009.

54. Segal ZV, Williams JMG, Teasdale JD. Mindfulness-based cognitive therapy for depression: a new approach to preventing relapse. New York: Guildford; 2002.

55. Cohen S, Kamarck TRM. A global measure of perceived stress. J Health Soc Behav. 1983;24:385-96.

56. Spitzer RL, Kroenke K, Williams JBW, Lowe B. A brief measure for assessing generalized anxiety disorder: the GAD-7. Arch Intern Med. 2006;166:1092-7.

57. Kroenke K, Spitzer RL, Williams JBW. The PHQ-9: validity of a brief depression severity measure. J Gen Intern Med. 2001;16:606-13.

58. Schaefer JA, Moos RH. Relationship, tasks, and system stressors in the health care workplace. J Community Appl Soc Psychol. 1993;3:285-98.

59. Karasek RA. Job demands, job decision latitude and mental strain: implications for job redesign. Adm Sci Q. 1979;24:285-308.

60. Astrom S, Nilsson M, Norberg A, Sandman P, Winblad B. Staff burnout in dementia care - relations to empathy and attitudes. Int J Nurs Stud. 1991;28:65-75.

61. Andrews FM, Withey SB. Social indicators of well being. In: Fields DL, editor. Taking the measure of work: a guide to validated scales for organizational research and diagnosis. London: Sage; 2002

62. Lintern T, Woods B, Phair L. Training is not enough to change care practice. JDC. 2000;8:15-6.

63. Koopman C, Pelletier KR, Sharda RN, Berger ML, Turpin RS, Hackleman P, et al. Stanford Presenteeism Scale: health status and employee productivity. J Occup Environ Med. 2002;44:14-20.

64. Ware JJ, Kosinski M, Keller SD. A 12-item short-form health survey: construction of scales and preliminary tests of reliability and validity. Med Care. 1996;34:220-33.

65. National Institute for Health Research. The ENRICH toolkit: Enabling Research in Care Homes; a simple guide for researchers, care home staff and residents. www.enrich.nihr.ac.uk/. Accessed 16 Jun 2015

\section{Submit your next manuscript to BioMed Central and we will help you at every step:}

- We accept pre-submission inquiries

- Our selector tool helps you to find the most relevant journal

- We provide round the clock customer support

- Convenient online submission

- Thorough peer review

- Inclusion in PubMed and all major indexing services

- Maximum visibility for your research

Submit your manuscript at www.biomedcentral.com/submit
Biomed Central 